\title{
Flexural Performance of RC Beams Strengthened by Carbon Fiber Reinforced Polymer (CFRP) Laminates
}

\author{
Steve Efe ${ }^{1}$, Jacob Oluwoye ${ }^{2}$ \\ Department of Civil Engineering, Morgan State University, Baltimore Maryland, U.S. \\ ${ }^{2}$ Alabama A and M university, Huntsville, Alabama, U.S
}

\begin{abstract}
The use of composite materials and strengthening systems have gained attention for structural reinforcement and strengthening solutions in concrete, masonry and timber structures in need of repair or upgrade. While many studies have addressed external strengthening of undamaged concrete members with various spacing of the wrappings, design considerations such as member cross-section, stirrup and reinforcement ratio, and level of strengthening, little or no information exist on repair of previously damaged members. This paper seeks to consider the performance of prior-damaged reinforced concrete $(\mathrm{RC})$ beams strengthened by externally bonded carbon fiber reinforcement polymer (CFRP) laminates to enhance the beam's load carrying capacity and failure mode. The five (5) beam specimens $(1$ plain concrete beam, 1 control RC beam-B1, 1 pre-loaded CFRP-B2 wrapped RC beam-B3, and 2 CFRP wrapped RC beams-B4 and B5) of dimensions of $100 \mathrm{~mm} \times 200 \mathrm{~mm} \times 1520$ $\mathbf{m m}$ were reinforced with two $12.7 \mathrm{~mm}$ diameter bars as main reinforcements, two $9.5 \mathrm{~mm}$ diameter two-legged stirrups spaced at $150 \mathrm{~mm}$ with a clear cover of $25 \mathrm{~mm}$. CFRP strips of width of $25 \mathrm{~mm}$ and a length of $400 \mathrm{~mm}$ were epoxy bonded to the underside of the CFRP wrapped beams with a centreto-centre spacing of $120 \mathrm{~mm}$. Ultimate loads, load-deflection relation and failure pattern were recorded for each beam as the beam failure progression and damage states were observed. The results of the study indicate that, 1) there is a marginal increase in first crack and ultimate loads. The first crack load increase was $15-40 \%$, while that in the ultimate load was between $5-18 \%$; 2) the CFRP wrapped beams experienced a flexural mode and found to be due to debonding of the FRP wraps.
\end{abstract}

Keywords: Concrete; fabrics; FRP; repair; shear

\section{INTRODUCTION}

The degradation of infrastructure in and around the world requires urgent attention in the form of replacement, rehabilitation or repair. Concrete structures deterioration or damage during its lifetime can be due to physical (abrasion, wear, earthquake, overloading, impact, erosion, thermal expansion, settlement freeze-thaw cycles, etc.), chemical factors (sulphate attack and corrosion of rebars), and construction and design deficiencies. On many occasions, corrosion of rebars may trigger off cracking and spalling of concrete, coupled with deterioration in the strength of RC structural members. The response and service life of such structures is greatly altered as a result and such situations call for repairs of affected zones and sometimes replacement of the entire structure (Esfahani et al. 2007). Various techniques are available for concrete structures repair and rehabilitation to close-up defect and mitigate failure. Steel plate bonding, steel jacketing and FRP sheets are methods of choice in strengthening of structural members. FRP laminates are widely used as external reinforcement compared to steel plate due to high tensile strength, high strength-weight ratio and corrosion resistance, however bond degradation and installation difficulty are still some challenges to overcome.

Externally bonded FRP laminates and fabrics can be used to increase the capacity of corroded beams as well as its shear and flexural strength (Ashour et al. 2004). These FRP laminates which are manufactured as sheets or strips by pultrusion are typically made of unidirectional or bidirectional carbon or glass fiber epoxy bonded to concrete structures. Sing-ping Chiew et al (2007) conducted an experimental study on the flexural performance of retrofitted beams wrapped with FRP laminates which were bonded to the tension face of the flexural RC beams. The study found out that the strengthening ratio increases linearly with the increase of the axial rigidity of the external CFRP laminates. Jumaat et al. (2010) evaluated the effectiveness of external strengthening on RC beams cracking moment, maximum moment, deflection, and crack patterns. An increase (up to $110 \%$ ) in the cracking moment of the CFRP repaired beams was noticed. The deflection decreased inversely with the number of CFRP layers on each beam. This, alternatively, caused the stiffness to increase while the crack patterns are different between the control and the CFRP repaired beams. The control had wider cracks while the repaired beams showed smaller cracks at failure. Also ACI 440 documents the effectiveness (up to $160 \%$ ) of FRP laminate external bonding to improve the capacity of RC members. While many studies have addressed external strengthening of undamaged concrete members with having various spacing of the wrappings, design considerations such as member cross-section, stirrup and reinforcement ratio, and level of strengthening, little or no information exist on repair of previously damaged members. With nearly one-third of the highway bridges in the United States currently in need of repair or replacements, innovative bridge concepts and 
construction methods to maintain the structural integrity and cost saving and cost-effective maintenance are vital (Thompson et al. 2007). In many cases, damages to highway infrastructure and bridges due to over-height collisions can be significant problem. This paper thus seeks to evaluate the flexural performance of damaged $\mathrm{RC}$ beams retrofitted with CFRP wraps.

\section{METHODOLOGY}

\section{A. RC Specimen}

All the five beams used for this experiment were designed according to ACI 318-16 and ACI 440.2R.08 to fail in flexure. The RC beams dimensions were $100 \mathrm{~mm}$ x $200 \mathrm{~mm} x$ 1520. Two No. 4 diameter bars were embedded at the bottom and top of the beam. No. 3 diameter bars were considered as two legged stirrups with a clear cover of $35 \mathrm{~mm}$ [1.5 inches] and spaced at $120 \mathrm{~mm}$ [ 4.8 inches]. The geometry, reinforcement and symmetric loading set up of the beams are shown in Figure 1. The concrete mix was designed according to ACI 211.4R-08, and the mix proportion was obtained as 1: 2.2: 3.0 with a water-cement ratio of 0.46 . For each casting (consisting of the plain, control beam and the beam to be wrapped), three 6 inches diameter and 12 inches height concrete cylinder were cast as companion specimens. The concrete mix proportions of the concrete constituent materials are shown in Table 1.

A waterproof, multipurpose adhesive based on solvent- free epoxy resin with a cure time of 10 hours at $20^{\circ} \mathrm{C}$. was used for the bonding of the fiber fabric to the repaired specimens.

Table 1: Concrete Mix Design Proportions

\begin{tabular}{ccc}
\hline Material & Weight, kN/m \\
\hline Ordinary Portland Cement & 3.23 \\
Water & 1.48 \\
Natural Sand & 7.06 \\
Coarse Aggregate 3/8 inches & 3.74 \\
Coarse Aggregate 1/2 inches & 7.55 \\
\hline
\end{tabular}

Table 2: Compressive strength of companion specimen and beams

\begin{tabular}{|c|c|c|c|}
\hline & Specimen 1 & Specimen 2 & Specimen 3 \\
\hline Average diameter, $\mathrm{m}$ & 0.15 & 0.15 & 0.15 \\
\hline Height, m & 0.3 & 0.3 & 0.3 \\
\hline Density, $\mathrm{kN} / \mathrm{m}^{3}$ & 23044.6 & 24018.5 & 23295.9 \\
\hline Maximum load at failure, $\mathrm{kN}$ & 123.2 & 139.7 & 113.9 \\
\hline Cylinder compressive strength, $\mathrm{kN} / \mathrm{m}^{2}$ & 34646.2 & 35148.9 & 34497.7 \\
\hline Average cylinder comp. Strength, kN/m² & & 34698.8 & \\
\hline
\end{tabular}

The formwork for the RC specimen was constructed to be rigid and water-proof and the beam steel cage consisting of the longitudinal bars and stirrup were placed in formwork. The concrete was mixed using a mixer, poured and compacted in the formwork. The concrete was left to cure for 30 hours using wet burlap at the Concrete Materials laboratory at Morgan State University before being tested. Two loading regimes were implemented: 1) Three point loading beam testing procedure was adopted and incremental loads of $10 \mathrm{kN}$ were applied in flexure to the beam until the ultimate load was reached. Data acquisition of deflection at the left, midspan and right of the RC beams was carried out using the linear variable displacement transducers (LVDT) which records at each loading interval as shown in Figure 1. Omega Pre-wired strain gauges of a length of $3 \mathrm{~mm}$ and resistance of $120 \Omega$ were attached to the stirrups in the shear span to measure strain as shown in
Figure 3. 2) The five beams were then unloaded, removed from the supports and three of the beams were repaired using CFRP fabrics. The Carbon Fibre Reinforced Polymer (CFRP) wraps of a width of 4 inches and a length of 100 inches were then glued to the bottom of three beams as shown in Figure 2. The CFRP wraps used had a Young's modulus of $120 \mathrm{MPa}$ and a tensile strength of $1516 \mathrm{MPa}$. The CFRP beams were divided into two groups. The first group consist of beams B-3 and B-4 were repaired using one layer of CFRP wraps applied to the beam, while the second group consisted of beam B4 were repaired using two layers of CFRP. These were loaded until failure or when flexural capacity was observed to be reached. The beam details and method of repair is given in Table 3 , and Table 4 shows the properties of the reinforcing bars obtained based on the experimental investigations. 
Table 3: RC Beam Details

\begin{tabular}{cccccc}
\hline Specimen id & Bottom Steel & Top Steel & Stirrups & Repair Material & $\begin{array}{c}\text { Number of FRP } \\
\text { Layers }\end{array}$ \\
\hline B1 & None & None & None & None & None \\
B2 & $2 \# 4$ & $2 \# 4$ & $2 \# 3$ & None & None \\
B3 & $2 \# 4$ & $2 \# 4$ & $2 \# 3$ & CFRP & 1 \\
B4 & $2 \# 4$ & $2 \# 4$ & $2 \# 3$ & CFRP & CFRP \\
B5 & $2 \# 4$ & $2 \# 4$ & $2 \# 3$ & 2 & 1 \\
\hline
\end{tabular}

Table 4: Reinforcement bar details.

\begin{tabular}{ccccc}
\hline Reinforcing bar & Elastic Modulus (MPa) & Diameter $(\mathbf{m m})$ & Yield Strength (MPa) & Ultimate Strength (MPa) \\
\hline Longitudinal & 200 & 12.7 & 470 & 620 \\
Stirrup & 210 & 10 & 380 & 550 \\
\hline
\end{tabular}

The stirrup spacing, beam aspect ratio $(\mathrm{a} / \mathrm{d})$ and provision of wraps around beam would affect the overall performance of the beams. All the beams have aspect $(\mathrm{a} / \mathrm{d})$ ratio of 2.6 and a stirrup spacing of 4 inches which is less than the maximum allowable spacing in ACI $440\left(\mathrm{~d} / 2\right.$ or 24 inches for $\emptyset v_{c} \geq$ $\left.v_{u}>\frac{\emptyset v_{c}}{2}\right)$. This was carried out to initiate possible flexural failure in the beam. Flexural failure with enhanced ductility and a marginal increase in the first crack strength are expected in wrapped beams B3, B4, and B5 beams.

\section{DATA ACQUISITION}

Deflections in the beams were measured using LVDT installed at three different locations as shown in Fig. 2. Strain gages were installed on stirrups of all the beams to measure strains as shown in Fig. 3. Beams were tested in a four-point bending test. The loading was realized as deformation controlled using hydraulic jacks with calibrated gauges. The first stage of the research was focused on recognizing the process of the crack's initiation in the plain concrete beam $\mathrm{B} 1$ and strengthened reinforced concrete beams B3, B4 and B5.

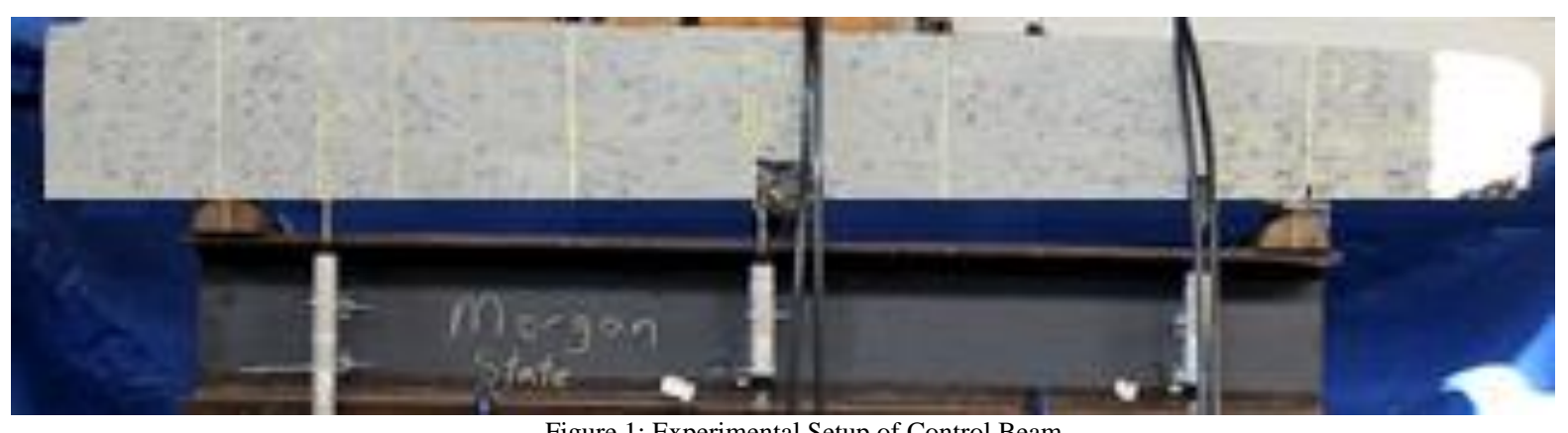

Figure 1: Experimental Setup of Control Beam

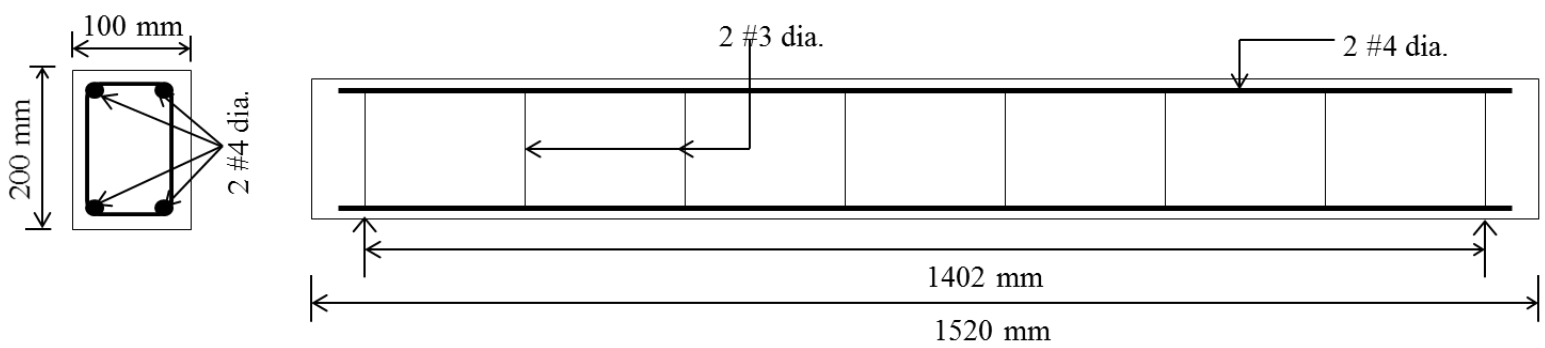

Figure 1: Longitudinal and cross-sections of the beam 

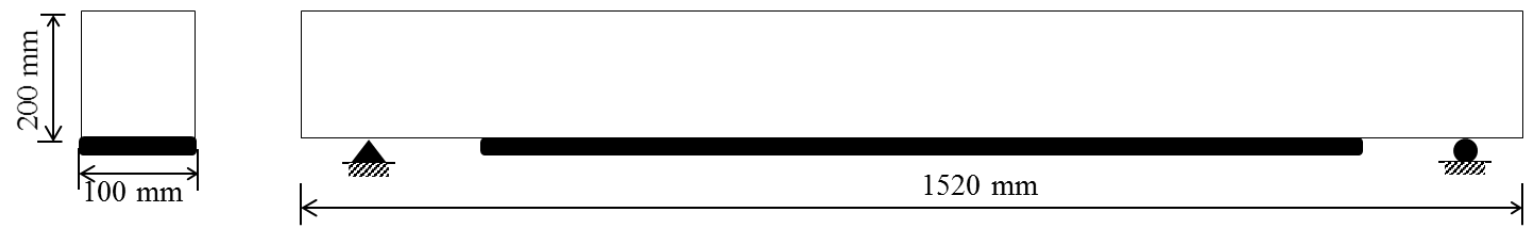

Figure 2: Strengthening scheme using CFRP wrapping

NR

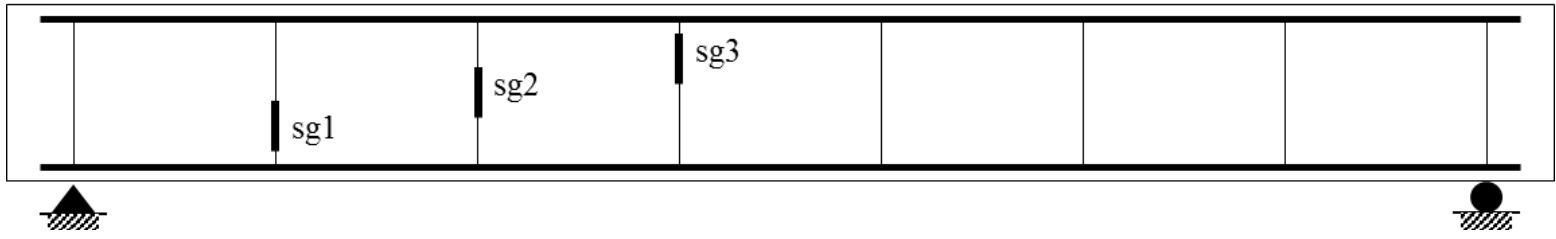

SR

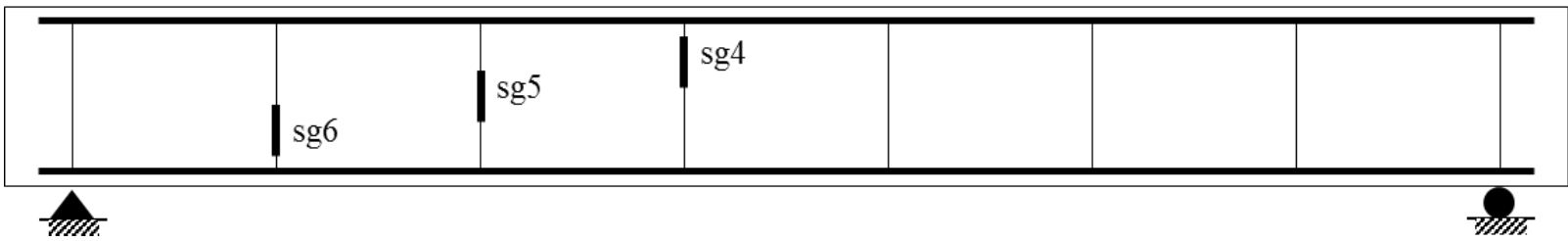

Figure 3: Location of embedded strain gauges (2 $\mathrm{mm}$ gauge length) on stirrup

\section{RESULTS AND DISCUSSIONS}

\section{A. $\quad$ Failure Mode and Loads}

Table 4 summarizes the outcomes of the flexural tests: the first crack load, the ultimate load, the measured deflection corresponding to the ultimate load and the failure mode. A brittle, sudden failure behavior was observed after the appearance of the first flexural crack in beam B1 during the experiment. The failure mode of the reference beam B2 is a typical bending failure pattern, i.e. the failure basically consists of flexural cracks in the constant moment section characterized by yielding of the longitudinal steel bars and the concrete crush in the compressive zone. For the beams strengthened with one or two layers of CFRP sheets, appearing of cracks was delayed, also the width of those cracks and the inter-space between cracks were reduced. There were two main failure modes for the beams strengthened, i.e. snapping and debonding of CFRP sheets, and shear cracks propagated toward the loading point accompanied by debonding of the CFRP sheets from the concrete. The failure mode of the beams, B3, B4, B5 and B6, was characterized by the snapping of one layer or two layers of CFRP sheets that were bonded on the tensile face of the beams. However, the beams of B5 and B6 failed by the debonding of CFRP sheets from mid span or loading point.

Table 5. Test results of the beams tested

\begin{tabular}{|c|c|c|c|c|}
\hline Beam & Crack Load, kN & $\begin{array}{l}\text { Ultimate Load, } \\
\mathrm{kN}\end{array}$ & Deflection, $\mathrm{mm}$ & Failure modes \\
\hline B1 & 12.54 & 17.36 & 4.22 & Brittle Failure \\
\hline B2 & 21.56 & 43.33 & 9.46 & Flexural Failure \\
\hline B3 & 31.95 & 48.15 & 13.1 & CFRP Snapping and Flexural Failure \\
\hline B4 & 33.72 & 60.62 & 10.20 & CFRP debonding and flexural failure \\
\hline B5 & 21.68 & 69.82 & 10.30 & CFRP debonding and flexural failure \\
\hline
\end{tabular}

The first crack loads of the beams B3, B4 and B5, which were strengthened with one and two layers of CFRP sheets respectively, are $32.5,36.0 \%$ and $49.0 \%$ higher than that of the reference beam B2, due to the restraining effect of CFRP sheets respectively. However, the first crack loads are not proportional to the number of layers of CFRP sheets applied. The beam B3 gives a higher crack load than that of beams B1 and B2 but lower than that of the beam B4 and B5 since the beams was preloaded and the cracks were developed before the final failure tests. As shown in Table II, the ultimate loads of the control beams B2 is $59.87 \%$ higher than that of the plain beam B1. The table also shows that there is no an apparent gain on the strength when the reinforcement is increased from one layer to two layers. The beam B5 gives the ultimate load of $69.82 \mathrm{kN}$, which is $30.4 \%$ and $13.2 \%$ higher than that of the beams B3 and B4, respectively. 
Results given in Table II also show that the beams strengthened perform better than the control beam with respect to load carrying capacity and ductility. However, preloading on the beams may likely results in a decrease in flexural strength and ultimate ductility.

\section{B. Load-deflection Behaviour}

Fig. 2 shows that the initial stiffness of beams strengthened increases significantly in comparison to the control beam due to the contribution from the CFRP reinforcement. Beam $\mathrm{B} 3$ gives a smaller deflection at the given load than that of beam B4 from zero loads to the load of $52 \mathrm{kN}$, since the cracks developed during the preloading degraded the beam stiffness [1]. The control beam B2 with longitudinal reinforcement has a higher stiffness than that of the plain beam (WR4) which had premature brittle failure. Overall, the beam B5 gives a higher stiffness and ultimate strength than all the tested beams, due to contribution of longitudinal reinforcement and two layers of the CFRP stip.

Beam B2: The beam failed due to concrete crushing at midspan after yielding of the tension steel. No shear cracks are observed as expected as the beams has a shear span of 12 inches and stirrup spacing of 4 inches. After failure, flexural cracks are observed in the beams throughout the span length. Significant strain readings were recorded from strain gauges sg1 and sg2 in the shear span and these strain readings are higher compared to other strain gauges sg3, sg4, sg5 and sg6 (Figs. $4 \mathrm{a}$ and $4 \mathrm{~b}$ ). All strain readings are nearly same at peak load, however, sg5 showed some variation before the tension steel yielded. Wider cracks are noticed near sg3 at failure of the beam.

Beams B3: The preloaded concrete beams B3 strengthened with one layer of CFRP fabric, failed due to yielding of steel followed by rupture of fabric and crushing of concrete at mid-span. After failure, flexural cracks are observed in the beams. Shear cracks are not observed. The sg1 and sg6 strain gauges were located in the shear span. As shown in Figure $4 \mathrm{c}$, It was noted that the strains in the $\mathrm{sg} 1$ and $\mathrm{sg} 2$ exhibited a steep increase after a load of $42 \mathrm{kN}$. The strain gauge sg5 recorded a steep increase in strain around the experimental peak load, which suggests that the failure occurred around the location of this strain gauge.

Beams B4: The concrete beams B4 strengthened with one layer of CFRP fabric, failed due to yielding of steel followed by rupture of fabric and crushing of concrete at mid-span. After failure, flexural cracks are observed in the beams. Shear cracks are not observed. Figure 4d shows that sg1 and sg6 strain gauges showed higher strain values compared to the other electrical strain gauges, similar to what was observed for the B2 control beam. It can also be seen that sg5 was mostly in compression, while the $\operatorname{sg} 2$ was always under tension.

Beam B5: The concrete beam B5 strengthened with two layers of CFRP fabric, failed due to yielding of steel followed by debonding of fabric at mid-span followed by crushing of concrete. The term debonding implies that, at failure, the carbon sheet/fabric separated from the resin without any concrete or resin attached to it. After failure, flexural cracks are observed in the beam and while shear cracks are not observed. After failure, the CFRP fabric is easily peeled off from the beam, and no concrete chunks stuck to the fabric. The strain gauges sg1 and sg6 showed higher strain values compared to other strain gauges The sg2 gauge near the peak load carried a higher degree of tension, which indicates a possible de-bonding and thus putting a demand on the stirrup to take the tension. In fact, the final de-bonding failure occurred near the sg2 gauge.

e of the scientific research was focused on recognizing the process of the crack's initiation in plain concrete and slightly reinforced concrete beams. The experimental investigation was performed on 3 plain concrete beams and 3 slightly reinforced concrete beams (reinforcement ratio $0.12 \%$ ). Beams were tested in a four-point bending test. The beams were loaded with two concentrated forces which were applied from bottom to top in one third of the span. The application of the upturned way of loading and the loading procedure by forcing displacement allowed to slow down the failure process and to observe crack developing precisely. The loading was realized as deformation controlled using hydraulic jacks with calibrated gauges.

The beams were made of normal strength concrete.

The first stage of the scientific research was focused on recognizing the process of the crack's initiation in plain concrete and slightly reinforced concrete beams. The experimental investigation was performed on 3 plain concrete beams and 3 slightly reinforced concrete beams (reinforcement ratio $0.12 \%$ ). Beams were tested in a fourpoint bending test. The beams were loaded with two concentrated forces which were applied from bottom to top in one third of the span. The application of the upturned way of loading and the loading procedure by forcing displacement allowed to slow down the failure process and to observe crack developing precisely. The loading was realized as deformation controlled using hydraulic jacks with calibrated gauges.

The beams were made of normal strength concrete. 


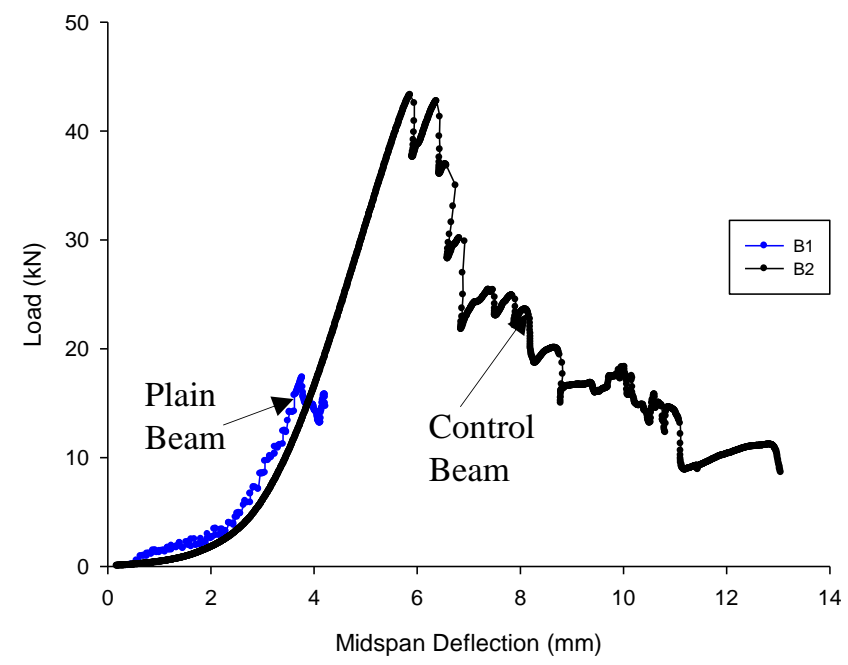

(a)

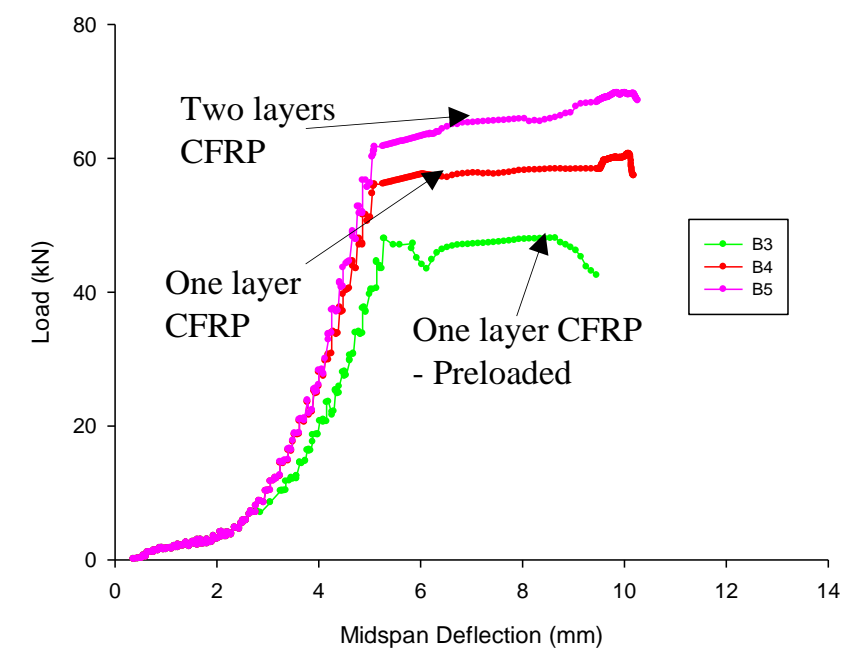

(b)

Figure 3. Load vs. deflection result of (a) Steel reinforced beam (b) CFRP strengthened beam

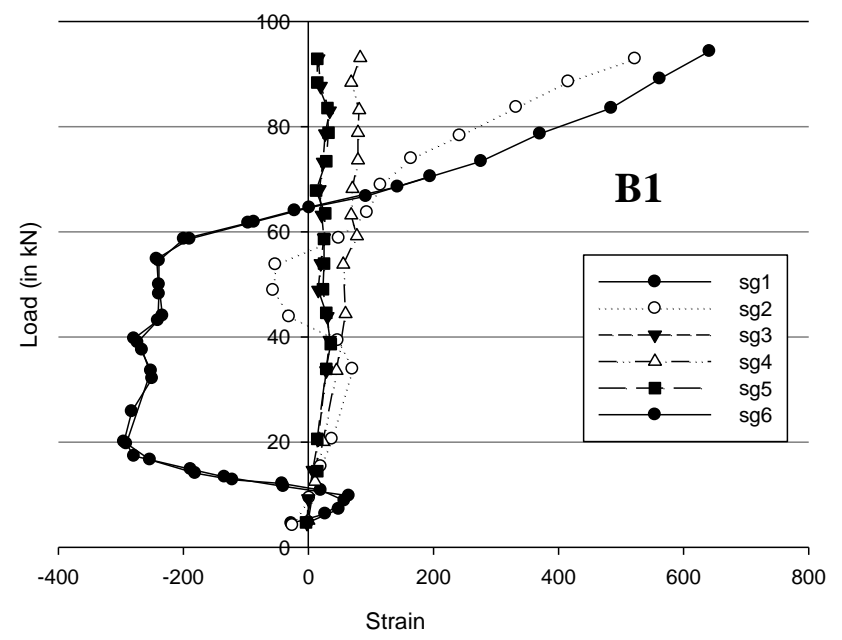

(a)

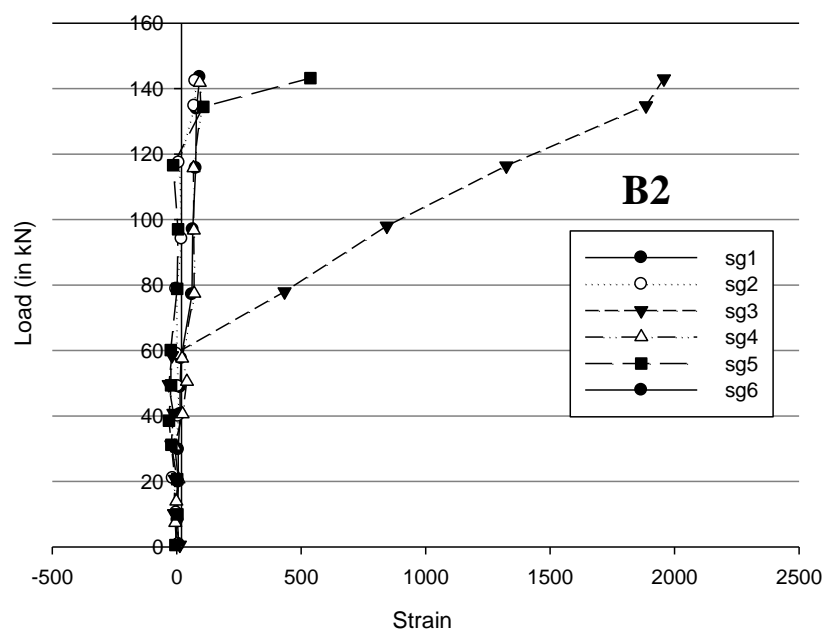

(b)

Fig. 4. Load-strain (in $\mu \varepsilon$ ) curves for (a) plain beam B1 (b) control beam B2 (c) Wrapped CFRP beam B3 (d) Wrapped GFRP beam B4 (e) WGFRP CFRP beam B5 


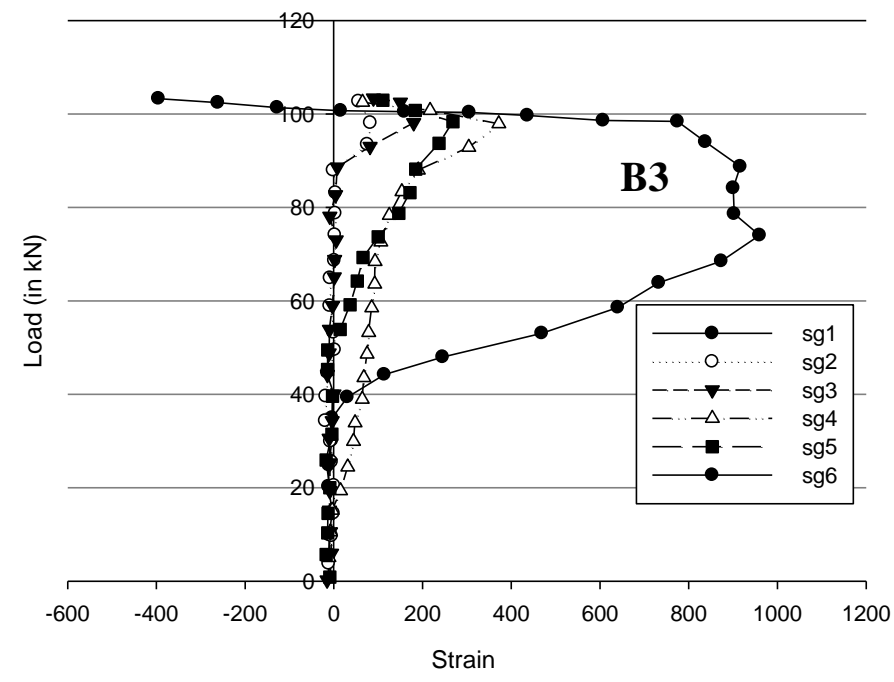

(c)

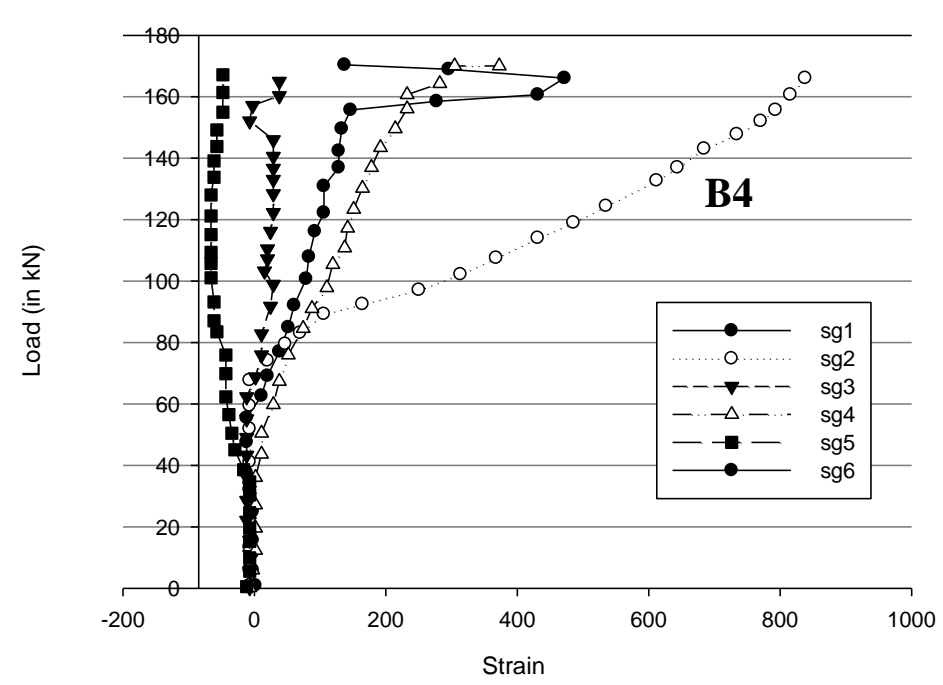

(d)

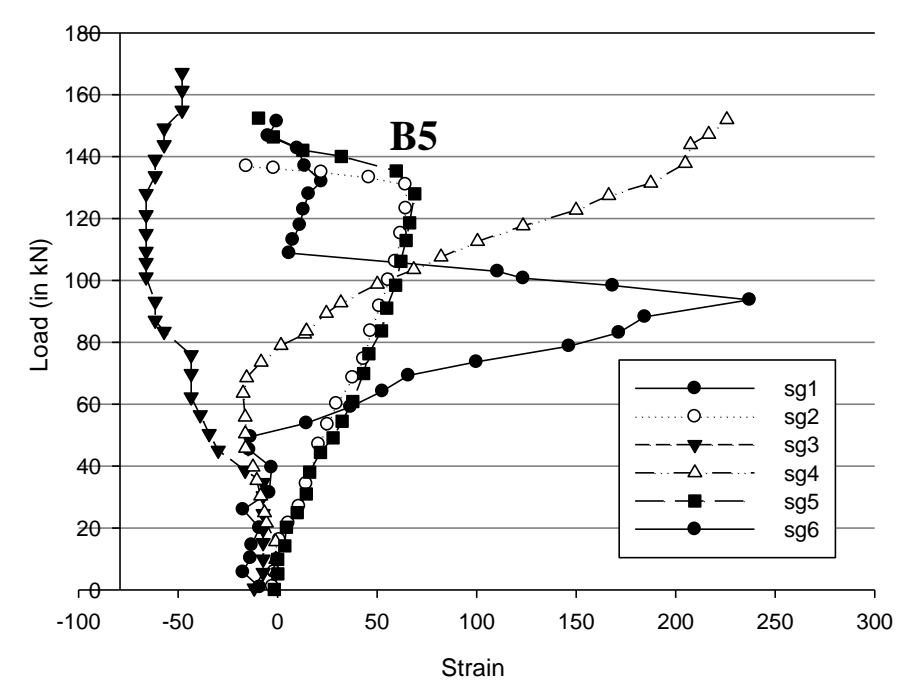

(e)

Fig. 8 Load-deflection curves for the three control beams

Fig. 4. Load-strain (in $\mu \varepsilon$ ) curves for (a) plain beam B1 (b) control beam B2 (c) Wrapped CFRP beam B3 (d) Wrapped CFRP beam B4 (e) CFRP CFRP beam B5

\section{Comparison with ACI 440.2R theoretical formulation}

In general, the proposed theoretical approach used for the flexural strength is based on the sectional analysis and strain compatibility.

Figure 5 shows the internal strain and stress distribution for a retrofitted rectangular section under flexure at the ultimate limit state. According to ACI 440.2R-17, the ultimate strength of the beam should satisfy strain compatibility and force equilibrium, and should consider the governing mode of failure. The flexural strength of the beams is given by

$$
M_{u}=M_{c}+M_{s}+M_{f}
$$

where, $M_{c}$ and $M_{S}$ are the contribution of the concrete and internal reinforcing steel bars 


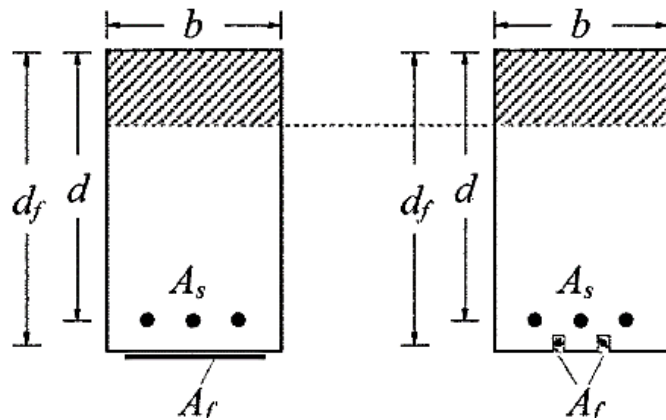

Reinforced Concrete Sections
Strain Distribution

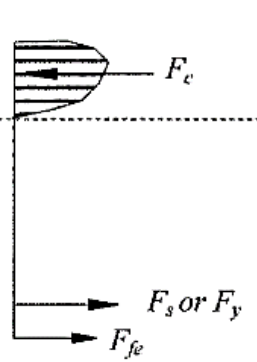

Force Equilibrium

(Non-linear Concrete Stress Distribution

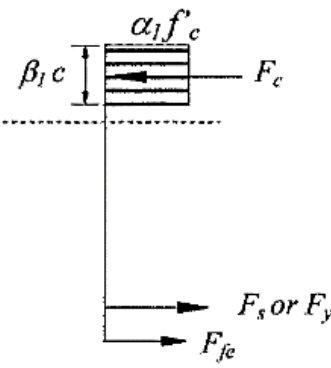

Force Equilibrium (Equivalent Concrete Stress Distribution

Figure 5. Internal strain and stress distribution for a rectangular section under flexure at ultimate limit state

The nominal flexural strength of the section with FRP external reinforcement is computed from

$$
M_{n}=A_{s} f_{s}\left(d \cdot \frac{\beta_{1} \cdot c}{2}+\Psi_{f} A_{f} f_{f} h \frac{\beta_{1} \cdot c}{2}\right)
$$

where $\psi \mathrm{f}$, is an additional reduction factor applied to the flexural-strength contribution of the FRP reinforcement. $A_{s}$ is the area of steel bars, $f_{s}$ is the stress in the steel (MPa), $d$ is the effective depth of the section, $A_{f}$ and $f_{f}$ are the area and stress level in FRP reinforcement respectively, and $c$ is the distance from extreme compression fiber to the neutral axis. The terms $\beta_{1}$ is a parameters defining a rectangular stress block in the concrete equivalent to the nonlinear distribution of stress. The values of the beam carrying capacity, $P_{\text {eqn }}$, estimated from equation 2 was compared to the test result, $P_{\text {exp }}$, of the CFRP wrapped beams B3, B4 and B5 and a ratio of $P_{\text {ana }} / P_{\exp }$ was evaluated in Table 6 . It can be concluded that the estimated values were quite lower than those of experimental ones. One possible reason for the difference between both the theoretical approaches and the experimental values can be found in the value of the maximum compressive concrete strain considered, because in all the theoretical approaches this value was the same as 0.003 .

Table 6: Comparison of Test Results and Theoretical Equation

\begin{tabular}{cccc}
\hline Beam & Ultimate Load, $P_{\exp }(\mathrm{kN})$ & ACI 440.2R-17, $P_{\text {eqn }}($ Eqn. 2) & $P_{\text {eqn }} P_{\text {exp }}$ \\
\hline B3 & 48.76 & 52.25 & 0.93 \\
B4 & 60.42 & 67.68 & 0.89 \\
B5 & 74.68 & 79.82 & 0.93 \\
\hline
\end{tabular}

\section{CONCLUSIONS}

The results indicated that the flexural carrying capacity of the RC beams strengthened using externally bonded CFRP sheets on bottom faces could significantly enhance the flexural capacity of the beams tested. The increase on the overall flexural capacity of the CFRP strengthened beams varies between $41 \%$ and $125 \%$ over the control beam. The strength and ductility for the beams strengthened could be enhanced significantly by providing effective bond, increasing the number of CFRP layers the longitudinal reinforcement ratio, but the preloading before the failure test might result in a little decrease in flexural strength, stiffness and ductility. It is noted that the final failure of the wrapped beams occurred due to the de-bonding of the wrap in the compression zone and failure was sudden.

\section{REFERENCES}

[1] Ashour, A. F., El-Refaie, S. A., \& Garrity, S. W. (2004) Flexural strengthening of RC continuous beams using CFRP laminates. Cement and concrete composites, 26(7), 765-775.

[2] Chiew, S. P., Sun, Q., \& Yu, Y. (2007). Flexural strength of RC beams with GFRP laminates. Journal of composites for Construction, 11(5), 497-506.

[3] Esfahani, M. R., Kianoush, M. R., \& Tajari, A. R. (2007). Flexural behaviour of reinforced concrete beams strengthened by CFRP sheets. Engineering structures, 29(10), 2428-2444.

[4] Jumaat, M. Z., Rahman, M. M., \& Alam, M. A. (2010). Flexural strengthening of RC continuous T beam using CFRP laminate: A review. International Journal of the Physical Sciences, 5(6), 619-625.

[5] Thompson, N. G., Yunovich, M., \& Dunmire, D. (2007). Cost of corrosion and corrosion maintenance strategies. Corrosion Reviews, 25(3-4), 247-262.

[6] American Concrete Institute - ACI 440.2R - A Guide for the Design and Construction of Externally Bonded FRP Systems for Strengthening Concrete Structures. 